\title{
COMMUNITY IMPLEMENTATION DYNAMICS: NUTRIENT MANAGEMENT IN THE NEW YORK CITY AND CHESAPEAKE BAY WATERSHEDS
}

\section{Glenn Sterner III}

PhD Candidate in Rural Sociology

The Pennsylvania State University United States

\author{
Ray Bryant \\ Soil Scientist \\ United States Department \\ of Agriculture Research Service
}

Peter J A Kleinman

Soil Scientist

United States Department

of Agriculture Research Service

\section{Jack Watson}

Professor of Soil Physics and Biogeochemistry The Pennsylvania State University

United States

\author{
Theodore Alter \\ Professor of Agricultural, Environmental, \\ and Regional Economics \\ The Pennsylvania State University \\ United States
}

The creation of natural resource management and conservation strategies can be affected by engagement with local citizens and competing interests between agencies and stakeholders at the varying levels of governance. This paper examines the role of local engagement and the interaction between governance levels on the outcomes of nutrient management policy, a specific area of natural resource conservation and management. Presented are two case studies of the New York City and Chesapeake Bay Watersheds in the US. These case studies touch upon the themes of local citizen engagement and governance stakeholder interaction in changing nutrient management to improve water quality. An analysis of these cases leads to several key considerations for the creation and implementation of nutrient management and natural resource management more broadly, including the importance of: local citizen engagement, government brokering and cost sharing; and the need of all stakeholders to respect each other in the policy creation and implementation process.

\section{Introduction}

Much discussion of the policy development process is on the actual language surrounding the policy statute itself - its wording, implications, intended outcomes, and implementation. In this regard, the policy-making process is mostly technocratic. Often neglected in this consideration are the perspectives of local citizens who are at the centre of policy implementation. Economic incentives, which rely on behavioural assumptions, are often touted as an effective approach to change the behaviours and practices of local citizens. ${ }^{1}$ Economic incentives built into policies may increase the implementation of certain changes, but increasing the adoption rates through changes to local practices requires attention to the motivations of citizens. ${ }^{2}$ As illustrated with the following examples, local citizen implementation of changes, in practice, is influenced by complex interacting human, psychological and institutional factors, such as beliefs, values (eg, attachment to the land) and knowledge and risk perception. ${ }^{3}$ Effective regulatory design requires anticipation of the risks, unintended consequences, and citizen reaction to policy implementation by engaging communities at the very early stages of the policy-making process.

For example, Dutcher found that implementation of stream reforestation (an important practice for protecting stream water quality) can involve practical considerations which can be a surprise to those unfamiliar with local conditions. ${ }^{4}$ From a survey of landowners in a portion of the Chesapeake Bay watershed in Central Pennsylvania, he found that some rural residential landowners cut back riparian vegetation to keep away copperhead snakes from their children and grandchildren. Any effort to increase stream reforestation as a best

\footnotetext{
L S Prokopy, 'Determinants of Agricultural Best Management Practice Adoption: Evidence from the Literature’ (2008) 63 Journal of Soil and Water Conservation 300, DOI: 10.2489/jswc.63.5.300.

2 R L Ryan, D L Erickson and R De Young, 'Farmers' Motivations for Adoption Conservation Practices Along Riparian Zones in a Mid-Western Agricultural Watershed' (2003) 46 Journal of Environmental Planning and Management 19, DOI: $10.1080 / 713676702$.

4 D Dutcher, Landowner Perceptions of Protecting and Establishing Riparian Forests in Central Pennsylvania (Doctoral Dissertation, The Pennsylvania State University, 2000).
}

3 Ibid. 
management practice must, therefore, address landowner concerns about poisonous snakes - a consideration that only local knowledge could bring to the table. Practical considerations, such as difficulty and expense in maintaining implemented practices, aesthetic issues associated with local landowner and community expectations (eg, the 'image' of what constitutes a well-managed landscape), and perceived landowner and water quality benefits (eg, improved farm animal health - reduced mastitis in cows) are critical components to local implementation. ${ }^{5}$ Weaver goes on to postulate that 'to design a buffer (a best management practice) with minimal emphasis on human use and activity is to design a failing buffer'. 6 The same author concludes, 'Understanding cultures and recognizing local knowledge are important for natural resource managers'. 7

There are several approaches to citizen participation in policy development and implementation, ranging from non-participation (manipulation of the public), to tokenism (such as informing or consulting the public) and citizen power (including partnership and citizen control). ${ }^{8}$ Greater emphasis on participatory strategies in natural resource management (NRM) policy creation and implementation indicates a greater likelihood of positive outcomes, but these approaches necessitate a nuanced understanding of community engagement strategies. ${ }^{9}$ Local citizen participation requires that citizens be involved throughout the creation and implementation process and engaged as equal stakeholders. This requires local citizen and experts to have mutual respect for each other's knowledge. ${ }^{10}$ When we engage local citizens, showing respect for the situation in which they exist and emphasising their inherent dignity, ${ }^{11}$ we appreciate and regard the human dimensions associated with natural resource management policy development and implementation. We submit that this dimension, which is often overlooked in the NRM policy-making process, is a central and critical component to successful outcomes of NRM. This research expands its current conceptualisation and practice in policy creation and implementation.

As discussed and highlighted later in this paper, an additional consideration in the policy creation and implementation process with the potential to influence policy outcomes is the interaction between local, state, and national government agencies, each with their own stake in a policy's outcomes. These stakeholders and their interests may shift and change over time, causing confusion and potential conflict throughout the policy development and implementation process, indicating a need to be clear about roles and responsibilities. ${ }^{12} \mathrm{At}$ times, national or state interests and goals may directly conflict with local priorities, or unclear agency jurisdiction may create grey areas for implementation roles and responsibilities. Due to the potential for conflict between the varying levels of government during policy development and implementation, those processes that engage a wide network of federal, state, and local governmental officials and stakeholders exhibit greater successes in their outcomes. ${ }^{13}$ Increasing communication between these levels of governance can help implementation practices, ${ }^{14}$ but effective communication presupposes a need for the development of relationships in NRM. ${ }^{15}$ Emphasising to local citizens the relevance of their practices to broader regional or national issues can increase their likelihood of compliance and engagement with external governance agencies. ${ }^{16}$ Focusing on processes that arrive at a collaborative resolution of issues between local citizens and

${ }^{5}$ T D Weaver, 'Barriers and Incentives to Stream Conservation: The Influence of Culture on Buffer Design and Implementation (MLA Project Department of Landscape Architecture, The Pennsylvania State University, 2013).

Ibid, 28.

Ibid, 35 .

Sherry R Arnstein, 'A Ladder of Citizen Participation' (1969) 35 Journal of the American Institute of Planners 216. DOI: $10.1080 / 01944366908977225$

9 C Harrington, A Curtis and R Black, 'Locating Communities in Natural Resource Management' (2008) Journal of Environmental Policy and Planning 199, DOI: 10.1080/15239080801928469.

${ }^{10}$ Frank Fischer, Citizens, Experts, and the Environment: The Politics of Local Knowledge (Duke University Press, 2000).

${ }^{11}$ Barbara A Misztal, 'The Idea of Dignity: Its Modern Significance' (2012) 13 European Journal of Social Theory 254, DOI: $10.1177 / 1368431012449237$.

${ }^{12}$ Charlotte Billgren and Hans Holmén, 'Approaching Reality: Comparing Stakeholder Analysis and Cultural Theory in the Context of Natural Resource Management' (2008) 25 Land Use Policy 550, DOI: 10.1016/j.landusepol.2007.11.004.

${ }^{13}$ R Plummer and J FitzGibbon, 'People Matter: The Importance of Social Capital in the Co-Management of Natural Resources' (2006) 30 Natural Resources Forum 51-62, DOI: 10.1111/j.1477-8947.2006.00157.x; M Reed et al, 'Who's In And Why? A Typology of Stakeholder Analysis Methods for Natural Resource Management' (2009) 90 Journal of Environmental Management 1933. DOI, 10.1016/j.jenvman.2009.01.001.

${ }^{14}$ K Prager et al, 'Soil Degradation, Farming Practices, Institutions and Policy Responses: An Analytical Framework' (2010) 22 Land Degradation and Development 32, DOI: 10.1002/ldr.979.

15 Tania Schusler, Daniel Decker and Max Pfeffer, 'Social Learning for Collaborative Natural Resource Management' (2003) 15 Society and Natural Resources 309, DOI: 10.1080/08941920390178874.

${ }^{16}$ Prager, above $\mathrm{n} 14$ 
the various levels of governance that develop and implement policy has a much greater likelihood of successful outcomes over time. ${ }^{17}$

We have two objectives for this paper. The first is to examine the interplay between different levels of government in NRM. This is to provide context for the creation and implementation of soil management policy, while also explicating the potential for conflict and cooperation between the complex natures of these governmental relationships. The second objective is to highlight the importance of citizen engagement in natural resource management policy creation and implementation. To achieve these objectives, we present two case studies from our experience in the US that highlight the complicated nature of natural resource management. These case studies focus on the interplay of agricultural nutrient management and water quality, two areas of natural resource concern that are increasingly in conflict. Soil nutrients are the essential elements that affect plant growth, health and production - most commonly of agricultural crops. ${ }^{18}$ Managing the availability of nutrients in soils requires, among other things, balancing trade-offs in supplying crops with adequate nutrients and minimising the potential that these nutrients enrich runoff water and adversely impact water quality. Balancing these trade-offs is also the focus of many nutrient management practices and policies. $^{19}$

This paper begins by framing the process of soil conservation and nutrient management policy development and implementation in the US. We then detail the case studies in the New York City and Chesapeake Bay watersheds. These two cases were selected because each provides excellent insight into the complex nature of nutrient management policy creation and implementation between federal, state and local levels of governance. Additionally, the community engagement approach in the New York City watershed contrasts with the Chesapeake Bay watershed approach. The officials working with the New York City watershed took a proactive approach to engaging with local citizens; their work is internationally recognised for its successful management practices. ${ }^{20}$ However, the Chesapeake Bay watershed officials favoured a more expert-driven and technocratic approach, and they continue to struggle with effectively managing the watershed to increase positive outcomes. We provide results of our analysis of these case studies, concluding with a discussion and closing remarks regarding the dynamics of soil and nutrient management policy development and implementation, and the role of local citizens and communities. We find that the type of engagement with local citizens during the policy creation and implementation process affects the effectiveness of outcomes. Additionally, the level of government (local, state or federal) can have an effect on policy creation and implementation, indicating the need for intentional and careful consideration of this aspect of the process to ensure it does not impede the progress of these efforts. An equally important aspect of the effectiveness of policy implementation is the cost sharing mechanisms created to fund the needed changes of local management practices. Finally, respecting the dignity and situations in which local citizens exist is a critical component to enhance the effectiveness of engagement strategies in natural resource management policy creation and implementation.

\section{US soil and nutrient management policy development and implementation}

Soil conservation policy in the US has its origins predominantly in the devastating soil erosion events of the 1920 s and 30s, which stemmed from a severe drought and poor agricultural practices. ${ }^{21}$ Out of these tragedies, policymakers began implementing new policy and management strategies. Between 1982 and 1997, the amount of land under soil conservation practices increased by 46 million acres (about 19 million hectares). ${ }^{22}$ Likewise, systematic nutrient management has been pursued for quite some time, though most programs emerged in the

\footnotetext{
17 Thomas G Measham, 'Building Capacity for Environmental Management: Local Knowledge and Rehabilitation on the Gippsland Red Gum Plains’ (2007) 38 Australian Geographer 145-159, DOI: 10.1080/00049180701392758.

${ }^{18}$ Les E Lanyon and Douglas B Beagle, A Nutrient Management Approach for Pennsylvania: Introduction to the Concepts (2003) Pennsylvania Nutrient Management Program: Agronomy Facts <http://pubs.cas.psu.edu/FreePubs/pdfs/uc107.pdf>. 19 Ibid.

${ }^{20}$ M Pires, 'Watershed Protection for a World City: The Case of New York' (2004) 21 Land Use Policy 161, DOI: 10.1016/j.landusepol.2003.08.001.

21 USDA Natural Resources Conservation Service, 75 Years Helping People Help the Land: A Brief History of NRCS (nd) <http://www.nrcs.usda.gov/wps/portal/nrcs/detail/national/about/history/?cid=nrcs143_021392>. 22 Ibid.
} 
$20^{\text {th }}$ century. ${ }^{23}$ These policies revolve around practices that aim to reduce nutrient pollution by implementing practices guided by soil tests and standards for nutrient quality. However, in both soil and nutrient management policies, the same practices have not been used the same way in every case. As many policymakers note, no single approach is effective all the time. The approaches to policy implementation are just as diverse as the practices themselves.

Since the start of the $20^{\text {th }}$ century, soil and nutrient management policy has been an important aspect of American government. The decisions that affect these policies emanate from the local, state and federal levels. And although the federal government has the most power over what that policy looks like, most experts agree that, because of its role 'on the ground', where policy gets translated into action, local government is crucial in any decision-making process.

In its recent publication, Energy Efficiency in Water and Wastewater Facilities, the US Environmental Protection Agency (EPA) points out the interplay between different levels of government and shows how this affects the effectiveness of soil management policy. ${ }^{24}$ At the core of most cases is local government. Counties, townships, and city councils often spawn new ideas about policy. Many of these local governments appoint advisory committees, which play an important role in policy outcomes. Local conservation district managers oversee implementation of these policies. In addition, local government officials provide key visibility for particular legislation and their support - or lack thereof - can make or break a soil management policy.

On a different level, state government departments provide local governments with resources and assistance in implementing new strategies. State governments often have the authority to overrule local governments, and such decisions would require adherence to new policies. Most environmental laws that are passed at the federal level by Congress come with a provision that allows laws to be delegated to state governments where they will be implemented and administered. ${ }^{25}$ When a program is delegated to a state, the state is in charge of permits, inspections, and enforcement duties that relate to the piece of legislation.

In the same way, the federal government can also take precedence over both state and local government. When Congress passes an environmental act, such as the Safe Drinking Water Act Amendments (1986), it becomes the new standard for policy across the nation. The federal government uses agencies like the EPA to create regulations that dictate what is and is not legal. The US Department of Agriculture (USDA) also cooperates with the EPA to organise dozens of programs that aim to expand economic opportunity through innovation and help rural America thrive. ${ }^{26}$ These agencies propose new policies, listen to feedback from the state and local levels, and then decide what makes it into the final statute. In this sense, the federal government clearly has the broadest and most impactful powers when it comes to soil management policy.

Engagement with local stakeholders can profoundly impact the outcomes, both negative and positive, of soil management policy. ${ }^{27}$ Nevertheless, this interplay leads to conflict throughout the American government among the different levels of administration. This disagreement defines many aspects of political philosophy, with conservatives typically urging for more power in the hands of local level decision makers and liberals generally attempting to empower the federal government with more responsibility. In this sense, soil and nutrient management policy affects, and is affected by, not only the environmental and natural resource landscape but also the socio-political and institutional landscape.

\section{Case studies}

We present two case studies that highlight the importance of considering the human and institutional dimensions of nutrient management. These case studies particularly emphasise the complicated jurisdictional nature of soil management policy in the US and the role of community engagement and participation in NRM policy development and implementation. The first case study highlights the New York City watershed with

\footnotetext{
${ }^{23}$ University of Maryland, History of Nutrient Management Planning in Maryland (nd) <http: / / extension.umd.edu/anmp/about/history-nutrient-management-planning-maryland >.

${ }^{24}$ Environmental Protection Agency, Energy Efficiency in Water and Wastewater Facilities (2013) <http://epa.gov/statelocalclimate/documents/pdf/wastewater-guide.pdf>.

${ }^{25}$ Environmental Protection Agency (EPA), Catalog of Environmental Programs 2012 (2012) <http://www.epa.gov/oig/catalog/>.

26 Ibid.

${ }^{27}$ Plummer, above n 13.
} 
specific focus on the issues of the Cannonsville Reservoir watershed. We then follow with the case of the Chesapeake Bay Watershed.

\section{The case of the New York City watershed - Cannonsville}

The New York City (NYC) Watershed Protection Program is internationally recognised as one of the most successful watershed management efforts in the world. ${ }^{28}$ Historical events that shaped the backdrop for watershed management, elements of the program that contributed to this success, and lessons learned are presented through the eyes of Cornell University and USDA Agricultural Research Service scientists who conducted research in the Cannonsville Reservoir watershed in the late 1990s shortly after the program was initiated.

\section{Watershed management issues}

The NYC watershed is a network of 19 reservoirs that supply approximately 1.3 billion gallons of high quality, unfiltered drinking water to the nearly nine million residents of NYC and suburban communities. During the past three decades, the Cannonsville Reservoir, located on the West Branch of the Delaware River in Delaware County, posed the greatest challenge among the 19 reservoirs for watershed management. Periodic algal blooms, usually in late summer, required it to be taken off-line for several weeks each year until water quality improved. The Cannonsville watershed became the test bed for watershed management efforts, and successes there served as models for other reservoirs in the NYC watershed and throughout the state.

In response to the Safe Drinking Water Act Amendments (1986), the EPA developed criteria under which filtration would be required for public surface water supplies. These included objective water quality criteria, operational criteria and watershed control criteria that were designed to minimise the potential for contamination by coliform bacteria, Giardia, viruses and disinfection by-products. An outbreak of Cryptosporidiosis in Milwaukee in 1993, which sickened 403000 and killed 104 residents, motivated the EPA to evaluate compliance with these water quality control criteria more closely. NYC was threatened with an EPA mandate to filter their water supply at a cost of US\$8 to $\$ 10$ billion to build a filtration plant, which required $\$ 1$ million per day to operate and maintain. However, in December 1993 EPA granted the city a Filtration Avoidance Determination that included the implementation of a land acquisition program and the promulgation of revised watershed regulations. Watershed residents objected quickly and vocally to these programs, which they viewed as further infringement on their rights for the benefit of city dwellers. To understand the fierce emotional reaction of watershed residents, one has to know the history of the building of the reservoirs.

\section{History of NYC watershed}

The development of the NYC water supply west of the Hudson River began in 1905 with the New York State (NYS) Legislature passing laws allowing the city to acquire lands and build dams, reservoirs and aqueducts in the Catskill Mountains, north and west of the city. The Cannonsville Reservoir, constructed from 1955 to 1965 , was the last chapter of an all too familiar story. When the reservoir was filled and put into service in 1967, water inundated 19910 acres (about 8000 hectares), displacing five communities and 941 people. The largest of these communities was the city of Cannonsville. People watched as their houses, barns, businesses and churches were levelled by bulldozers, burned and hauled away.

With the completion of the Cannonsville Reservoir, construction of the NYC water supply system was finished in 1965 but, in 1993, residents of the watershed again felt unjustly threatened by the proposed land acquisition program and the promulgation of revised watershed regulations.

The Cannonsville Reservoir has a surface area of about 5000 acres (2020 hectares), and the entire $355 \mathrm{mi}^{2}$ (914 $\mathrm{km}^{2}$ ) watershed lies within Delaware County. The physiography of the Cannonsville Watershed is characterised by narrow valleys that have steep walls and smooth floors. ${ }^{29}$ The ancestors of the current landholders came to the area over 200 years ago following the Revolutionary War. There are approximately 200 active large farms and the oldest farms have celebrated their bi-centennial. Roughly 70 per cent of the farms are in dairy and 15

\footnotetext{
${ }^{28}$ Pires, above n 20.

29 USDA-NRCS, Town Brook and Cannonsville Reservoir Watersheds, New York (2005)

<http://www.nrcs.usda.gov/Internet/FSE_DOCUMENTS/nrcs143_013487.pdf>.
} 
per cent produce beef, representing about 11000 dairy cows and 1300 beef cattle. ${ }^{30}$ Agricultural land uses within the $917 \mathrm{~km}^{2}$ (355 $\mathrm{mi}^{2}$ ) watershed consists of 2 per cent cropland (corn [Zea mays L] and alfalfa [Medicago sativa L]), 48 per cent pasture and hay, and 50 per cent agro-forestry. Although the total amount of cultivated cropland is relatively minor, those fields are located in valley bottoms close to streams and rivers, receive most of the nutrients in the form of animal manure, and are on soils that are most sensitive to runoff. Barnyards and associated heavy animal use areas are also located close to streams and rivers, which supply water for the animal operations. The village of Walton is located on the West Branch of the Delaware River approximately ten miles upstream from the Cannonsville Reservoir, the largest municipality in the watershed (population 3300 in the mid-1990s).

\section{Sources of water quality issues}

As mentioned previously, regularly occurring algal blooms in the Cannonsville Reservoir and associated eutrophic conditions were the primary water quality concerns. The increased carbon in eutrophic water, when mixed with chlorine as a disinfectant, can result in chlorinated hydrocarbons that are suspected of being carcinogenic and may enhance the risk of early term miscarriages and birth defects. ${ }^{31}$ Excess nutrients, particularly phosphorus (P), fuel the growth of blue-green algae that are capable of fixing their own nitrogen. Therefore, limiting the amount of $\mathrm{P}$ in the water can control algal blooms. Total maximum daily loads (TMDLs), a calculation of the maximum amount of a pollutant that a water body can receive and still meet water quality standards, were established by EPA for all of the reservoirs in the NYC watershed and were based on the existing NYS recreational P guidance value of $20 \mu \mathrm{g} / \mathrm{L}$. The Cannonsville watershed was the only one of the nine watersheds west of the Hudson that did not meet its TMDL. Consequently, it was designated as P restricted, meaning that municipalities could not allow growth of new businesses that could provide jobs for residents if it would result in increased $P$ loading. Although the limited amount of monitoring data showed excessive $P$ loads from the Walton wastewater treatment plant, it was not clear that improved water treatment alone would result in reductions in $\mathrm{P}$ loads measured at the mouth of the reservoir sufficient to meet the TMDL. Immediately following the new regulations and restrictions, much finger pointing between village officials and the agricultural community occurred, with respect to the real cause of $\mathrm{P}$ loading in the watershed.

\section{Local engagement strategies}

Faced with such strong local opposition to new regulations and restrictions on land use and management, New York Governor George Pataki organised a broad group of stakeholders from EPA, various state and city agencies, environmental groups, and watershed residents and municipalities to begin negotiating a framework for advancing the watershed protection program. The negotiations resulted in the signing of the 1997 New York City Watershed Memorandum of Agreement (MOA), a partnership agreement between local residents and state and city agencies. Acceptance of this MOA by local residents could initially be characterised as a large leap of faith and opinions regarding various issues reflected in the agreement were far from unanimous. However, as promised resources materialised and local residents were given a voice that was heard and respected by NYC and NYS officials, trust among the various parties began to grow.

Watershed management efforts in the Cannonsville were successful on two fronts. First, a filtration avoidance determination was issued upon signing of the MOA in 1997 by the EPA, followed by NYC securing a five-year filtration avoidance determination in 2002, and in 2007 the determination was renewed for 10 years.

Additionally, after accounting for $\mathrm{P}$ reductions due to upgrading municipal waste water treatment systems in the Cannonsville Reservoir watershed that reduced $\mathrm{P}$ loads from point sources by an order of magnitude, monitoring data showed a 50 per cent reduction in dissolved $P$ and a 17 per cent reduction in total $P$ from nonpoint sources during the five-year period from 2000 to 2004 compared to the period from 1992 to $1999 .^{32}$ These data proved that implementation of nutrient management practices by the farming community helped to vastly improve the water quality in the Cannonsville Reservoir watershed. In spite of the initial resentment toward NYC for imposing their will over watershed residents and the frictions between urban interests and agricultural

\footnotetext{
${ }^{30}$ R T Bryant et al, 'Cannonsville Reservoir and Town Brook Watersheds: Documenting Conservation Efforts to Protect New York City’s Drinking water’ (2008) 63 Journal of Soil and Water Conservation 339, DOI: 10.2489/jswc.63.6.339.

31 I Gerhard et al, 'Chlorinated Hydrocarbons in Women with Repeated Miscarriages' (1998) 106 Environmental Health Perspectives 675-681.

32 P L Bishop, 'Update on Phosphorus Loading from WBDR Basin' (Working Paper, Division of Water, Bureau of Water Assessment and Management, New York State Department of Environmental Conservation, 2006).
} 
interests within the watershed, these successes can be first and foremost attributed to the partnership that was forged among all interested parties through the $1997 \mathrm{MOA}$ and the ensuing trust among the different parties that developed over time.

Key to the success of the partnership was the resources NYC was able to leverage. A payment to upstream local communities of US\$3 million per year over a period of more than 10 years to implement practices sounds like a lot of money, but calculations put the cost per NYC family using 100000 gallons (about half a megalitre) of water per year at only US\$2.20 per year for watershed protection. Nevertheless, there are few cases where resources of this magnitude are available to bring to bear on a water quality problem.

Also, key to the success of the partnership was the empowerment of the local partners. Formation of the Catskill Watershed Corporation (CWC) and the Watershed Agricultural Council (WAC), two locally-based, notfor-profit corporations headquartered in the Cannonsville Reservoir watershed, provided a voice for their respective constituents. The CWC represented urban municipalities within the watershed and was charged with oversight of community infrastructure and economic development programs, whereas the WAC represented the rural farming community and was charged with oversight of natural resource and conservation programs. Both corporations managed funds for local projects, provided by NYC, which empowered them to prioritise and implement watershed management actions to improve water quality while minimising negative impacts on watershed residents. Through the early years, the WAC managed a US\$3 million annual budget and provided 100 per cent cost share to farmers for Best Management Practice (BMP) installation and maintenance.

\section{Outcomes of engagement strategies}

Management required a balance between the application of technical information and the need to address social sensitivities. For example, the conservation technician could easily identify problems that, if addressed, would have the greatest impact on water quality. Although management issues that affect water quality could be found on all farms, most of the problems having the greatest impact on water quality could be found on a small fraction of the farms in the watershed. During the first five years that the WAC managed funds for BMP implementation, the goal was to gain participation by as many farmers in the watershed as possible. The first reason for doing so was to demonstrate that watershed residents were willing to participate directly. The second reason was to ensure WAC board members were not seen by their peers as playing favourites among their neighbours by providing resources to only a few farmers. Within five years they were successful in gaining nearly 100 per cent participation of local farmers by distributing resources to address real problems that affect water quality, but not necessarily targeting those having the greatest impact on water quality. Thereafter, priorities were shifted more toward addressing the problems that had the greatest impact on water quality.

Research and education played a major role in effective watershed management. Although fencing cattle out of a stream, and thereby preventing direct deposits of faecal matter in the stream, seems like obvious solutions, farmers were reluctant to do so. Fences require maintenance, and vegetation within the fenced area may require mowing and trimming to prevent it from clogging the waterway thereby increasing the extent of flood damage. Using readily available information on characteristics of dairy farms in the Cannonsville watershed, James ${ }^{33}$ estimated that, across the watershed, direct deposition of faecal matter into streams was the source of 10 per cent of annual $P$ loadings attributed to all agricultural sources. Farmers, faced with these facts that were derived within the Cannonsville watershed, were more willing to implement stream bank fencing.

Many of the challenges experienced in this watershed related to BMP implementation can be directly and indirectly related to historic experiences of the farmers and other local residents, and what they viewed as the heavy-handed approach taken by NYC in the development of the Cannonsville Reservoir in the 1950s and 1960s as well as earlier activities associated with confiscation of private lands by NYC by eminent domain: ${ }^{34}$ in 1905 , the NYS legislature allowed for the NYC Board of Water Supply to acquire, by eminent domain, lands outside of city jurisdiction for reservoir development. ${ }^{35}$ NYC's reservoirs came at a cost to watershed inhabitants,

\footnotetext{
${ }^{33}$ E James et al, 'Phosphorus Contributions from Pastured Dairy Cattle to Streams of the Cannonsville Watershed, New York' (2007) 62 Journal of Soil and Water Conservation 40.

${ }^{34}$ A E Armstrong et al, 'Influence of Resentment in the New York City Conservation Reserve Enhancement Program' (2011) 66 Journal Soil Water Conservation 337, DOI: 10.2489/jswc.66.5.329.

${ }^{35}$ Pires, above n 20.
} 
displacing residents and confiscating private land holdings as early as 1915 to build reservoirs. ${ }^{36}$ The Cannonsville Reservoir, part of the Catskill-Delaware system, was the last constructed in the supply system. ${ }^{37}$ Research by Armstrong et al has documented that the level of 'resentment' by local landowners toward the aggressive NYC land procurement effort to reduce water pollution was highly correlated with lack of farmer adoption of BMPs in the watershed. ${ }^{38}$ They report that Conservation Reserve Enhancement Program (CREP) adopters of BMPs 'held significantly less resentment towards NYC than nonadopters' ${ }^{39}$ Thus, it would seem that historic policies which disregarded the dignity of those impacted by programmatic implementation (such as the eminent domain procurement of Cannonsville lands in the early 1900s) yielded negative results 80 or 90 years later, inhibiting the degree of success in the implementation of soil management practices. Citizen engagement efforts in more recent years, as illustrated in this case history, corrected this issue leading to greater success within the watershed.

\section{The case of the Chesapeake Bay watershed}

The Chesapeake Bay lies several hundred miles south of New York's Cannonsville Reservoir, approximately a four-hour drive by car. The Bay's $64000 \mathrm{mi}^{2}\left(165000 \mathrm{~km}^{2}\right)$ watershed wraps around the west and north of the Cannonsville reservoir's $450 \mathrm{mi}^{2}\left(1200 \mathrm{~km}^{2}\right)$ watershed. As with the Cannonsville Reservoir, the Chesapeake Bay has long been threatened by accelerated eutrophication from point and non-point source nutrient loadings, in addition to aquatic habitat loss from sediment accumulation. As with the Cannonsville Reservoir, efforts to curtail nutrient loadings to the Bay via point source controls have only served to highlight the importance of non-point sources. Today, it is estimated that non-point sources account for at least 75 per cent of the Chesapeake Bay's nitrogen $(\mathrm{N})$ and $\mathrm{P}$ loads.

\section{History of the Chesapeake Bay watershed}

Despite the proximity and similarity in nutrient loading concerns between the Chesapeake Bay and Cannonsville watersheds, the two watersheds differ profoundly in many aspects - as might be expected on the basis of size alone: 87000 farms in the Chesapeake Bay watershed versus 200 farms in Cannonsville; 17 million versus less than 50000 inhabitants; covering six US states (Delaware, Maryland, New York, Pennsylvania, Virginia, West Virginia) versus location within the boundary of one county in the NYS. In addition to differences in demographic and political scale, the Chesapeake Bay presents a much longer history of settlement and exploitation, from the founding of the Jamestown colony in 1607 along the Bay's James River tributary, to the establishment of major urban centres along its tributaries (Baltimore in 1729; Washington in 1790), to the fishing, farming and forestry traditions that fed, clothed and housed citizens of a new nation. Concerns over the health of the Bay and its tributaries extend back to the early years of the republic, producing some of the oldest zoning, conservation and water resource regulations in North America.

The Chesapeake Bay's policy history has been punctuated by periodic action aimed at protecting the resources of the Bay and its tributaries. ${ }^{40}$ While the complete history of Bay-related soil and nutrient management policies is worthy of note, it is the repeated practice of coordinating policies across governing bodies that has made the Chesapeake Bay particularly interesting. Beginning in 1787, George Washington oversaw the negotiation of the Mount Vernon Compact between Maryland and Virginia that established common regulations for commerce, fishing and navigation in some of the Bay's major tributaries and provided one of the earliest models for interstate agreements outside of the new nation's Articles of Confederation. Following the growth of the nation's environmental movement in the 1960s, new interstate laws were established around the Bay's tributaries themselves, such as formation of the Susquehanna River Basin Compact in 1970 involving Maryland, Pennsylvania and New York in partnership with the federal government. The Susquehanna River is the Bay's largest tributary and contributes roughly half of the Bay's freshwater, making the Susquehanna River Basin Commission an essential regulatory partner in Bay watershed remediation.

\footnotetext{
${ }^{36}$ Ibid.

37 Ibid.

${ }^{38}$ Armstrong et al, above n 34 .

39 Ibid, 340

${ }^{40}$ Howard R Ernst, Chesapeake Bay Blues: Science, Politics, and the Struggle to Save the Bay (Rowman and Littlefield Publishers, 2003).
} 


\section{Watershed management issues}

In the 1970s, the Chesapeake Bay was one of the first major water bodies to be recognised as suffering from lack of oxygen in the water, resulting in a seasonal 'dead zone'. During this period, the nation's major environmental regulations were implemented, notably the Clean Water Act (1972), with the EPA as their principal enforcer. States within the Chesapeake Bay watershed grappled with appropriate legislative response to the Bay's problems and, in 1980, the Chesapeake Bay Compact was signed with the objective of providing legislative guidance. By 1987, Pennsylvania had joined the Bay Compact and a series of agreements were established to restore the health of the Bay. Despite some progress, milestones for reducing nutrient and sediment loads to the Bay were repeatedly missed. As a result, interstate agreements were re-crafted in 1987, 1992 and 2000, and a variety of laws aimed at tackling aspects of Bay remediation were implemented by single states.

\section{Local engagement strategies}

The lengthy and complex history of Chesapeake Bay watershed regulations has been accompanied by polarisation of positions by various stakeholder groups. While nearly all stakeholder groups in the Bay's watershed community have backed the objectives of pollution reduction and Bay restoration, outcomes are often detoured by disagreement between stakeholders that reflect a diversity of competing priorities. These competing stands (eg, up-watershed states versus Bay-bordering states; municipal sewage treatment nutrient additions versus agricultural non-point source nutrient additions) may be observed in nearly all facets of Chesapeake Bay remediation activities, from research to outreach to action. Divisions frequently fall out along urban and rural divides. For instance, frustration exists amongst the farming community that their activities are not perceived by consumers as directly tied to food production, with consumer demand for cheap food driving low cost rather than environmental quality as a priority. Finally, strong political division exists along the lines of federal and states' rights, reflected locally and nationally in the regular reference to Chesapeake Bay pollution and pollution control regulations by conservative and liberal commentators alike.

By 2009, in the absence of sufficient improvements in Chesapeake Bay water quality, President Obama placed the Bay at the fore of his federal environmental agenda, through a presidential decree naming the Bay a national treasure, followed by one of the defining regulatory actions of his presidency: the Chesapeake Bay TMDL. In 2011, the US EPA, prompted by a lawsuit, determined that the six states in the Chesapeake Bay watershed and the District of Columbia had failed to meet the Clean Water Act requirements for protecting the Bay. Consequently, the agency imposed a TMDL on the Bay watershed, defining a maximum allowable pollution load for the Bay and mandating action to reduce nutrient ( $N$ and $P$ ) and sediment loads to the Bay. The TMDL, the largest ever imposed, required the six states in the Chesapeake Bay watershed and the District of Columbia to propose watershed implementation plans promising an array of point and non-point source control activities to achieve a roughly 25 per cent reduction in nutrient loads and a 20 per cent reduction in sediment loads by the year 2025. Given the size of the Bay watershed, 92 TMDLs had to be combined to form the Chesapeake Bay TMDL. While extensive, long-term water quality monitoring has existed within the Bay watershed, the process of tracking trends in water quality across the 92 jurisdictions could not be achieved with monitoring alone. Thus, the EPA's Chesapeake Bay Program has had to rely upon simulation modelling by a suite of models referred to, collectively, as the Chesapeake Bay Model.

\section{The Chesapeake Bay Model}

The Chesapeake Bay Model began its life as an 8.6 acre (3.5 hectare) concrete representation of the Bay itself, housed within a 14.5 acre (6 hectare) structure near Matapeake, on land donated by the state of Maryland. Designed in 1967 by the US Army Corps of Engineers to offer physical observations of the hydraulic consequence of activities such as dredging, this 1976 physical version of the Bay Model was replaced in 1981 with a computer simulation model that now serves as the primary arbiter of the Bay TMDL. Long used to guide recommendations by the Chesapeake Bay Program, the modern Chesapeake Bay Model has expanded from the original focus on Bay hydraulics to a broad representation of the entire 64000 square mile watershed, relying upon a broad suite of computational components that is so complex and arcane that it is difficult for even Bay Program experts to describe. So important is today's Bay Model to watershed decision-making that it has been the target of frontpage exposés in The Washington Post and the initial focus of litigation aimed at upending restrictions imposed by the Chesapeake Bay TMDL. While all appreciate the Bay model's utility to watershed management, even its proponents agree that the model has expanded well beyond its original intentions. 
As a framework for watershed management decisions, the Chesapeake Bay Model relies upon expert input and assessment to maintain its legitimacy, and serves as a lens through which watershed management activities are defined, categorised, evaluated and promoted or rejected. As a result of the use of experts for this process, local citizen knowledge is explicitly excluded from the Bay Model inputs. Efficiency factors quantify the relative effect of a management option on $\mathrm{N}, \mathrm{P}$ and sediment loadings to the Bay and its tributaries, determining whether a practice is identified as a 'best management practice' and assigning a pollution reduction value to the ultimate adoption of these practices. The development of efficiency factors involves input from limited local policy and watershed management experts.

Not surprisingly, each panel can be influenced by the composition of its experts, including by the stridency of their views. Indeed, local research is often elevated in consideration, nominally due to its greater relevance to conditions within the Chesapeake Bay watershed. Another general concern is that the efficiency factors themselves are arbitrary, forcing single values or ranges of values on practices whose performance is decidedly site specific and management dependent. Despite concerns, the resigned consensus among panellists is that the panels are serving a greater good, such that pragmatism tends to outweigh misgivings. Recently, a proposal has surfaced to allow public access to panel meetings, in an apparent effort to provide some oversight over panel deliberations. Such proposals reflect concern for greater public involvement.

\section{Outcomes of engagement strategies}

Reliance upon the Chesapeake Bay Model in shaping state management responses within the region has produced unexpected outcomes by the states charged with developing Watershed Implementation Plans. A key response to the TMDL has been for states to improve documentation of conservation practices already adopted by land managers but not quantified in the voluminous accounting libraries considered by the Chesapeake Bay Model. This very logical response has resulted in perceived expansion of practice adoption within the simulated realm of the Bay Model without any real expansion of practices within the Bay watershed. Similarly, state efforts to develop nutrient trading programs to apply cap-and-trade strategies to Bay mitigation have had to adapt to the framework of the Chesapeake Bay Model, whose scale of inference is decidedly incompatible with the site-specific trades that the programs promote. These outcomes, understood by a cadre of experts, can be bewildering to citizen groups working to influence real change in the landscapes of the Chesapeake Bay watershed.

Activities within the Chesapeake Bay watershed have helped to highlight the water quality trade-offs of particular management options, moving arcane debates into the polarising, public spotlight. Reduced tillage, that is, row crop production that minimises use of tillage implements in weed control and seedbed preparation, has expanded greatly. Reduced tillage systems tend to lower the energy and time required for field management activities, resulting in greater returns. Reduced tillage systems have been strongly advocated by conservation programs given their beneficial effect on soil conservation and soil health. Indeed, campaigns to expand reduced tillage have been exceptionally successful, with support from watershed and farming communities alike. However, minimising tillage also limits the extent to which nutrients, applied to the soil surface to fertilise crops, are redistributed through the soil. Consequently, farming systems with reduced tillage tend to concentrate nutrients at the soil surface where the nutrients are most vulnerable to environmental losses via surface runoff and volatilisation. The soil conservation and sediment load reduction benefits of reduced tillage must be weighed against fertilizer runoff (especially dissolved $\mathrm{P}$ ) and volatilisation (especially ammonia N).

It is not surprising, under the pressure of the Chesapeake TMDL - in a setting with a tendency to assign blame and to develop entrenched perspectives - that very different views have emerged on the role of reduced tillage in mitigating the agricultural contributions to Chesapeake nutrient and sediment loadings. Beyond debate over tillage, there continue to be numerous controversies in the development and implementation of nutrient management policy. Farmers on the Eastern Shore of Maryland argue that their land has a 'best use'; that is, to farm land best suited for agriculture - not to conserve it - assists in decreasing pollution and is imperative to the goal of providing food for national security. ${ }^{41}$ Financial incentives are important, as is reflected in results found for residential landowners in the Spring Creek watershed of central Pennsylvania. These landowners were found to be less willing to implement buffers than agricultural landowners, and the differences can be

\footnotetext{
${ }^{41}$ M Paolisso, P Weeks and J Packard, ‘A Cultural Model of Farmer Land Conservation’ 72 Human Organization 12.
} 
attributed to a heavier focus on conservation funding and programmatic support to agricultural landowners without effectively engaging non-agricultural landowners who have different expectations for their properties. $^{42}$

While this paints a bleak picture of the nutrient management practices and efforts in the Chesapeake Bay Watershed, there are pockets of engagement that are yielding positive reductions in nutrient and soil loadings. These success stories, while largely dispersed throughout the watershed, are grassroots-led and emphasise local partnerships with local citizens and experts to explore appropriate BMPs.

\section{Analysis}

Our objectives are to examine the interplay between different levels of government in natural resource management and highlight the importance of citizen engagement in natural resource management policy creation and implementation. We separate our analysis into these two objectives; it is important to note that these two are related to a certain extent as evidenced in our analysis. Within each objective, we draw out the themes from each individual case and then compare these themes across cases.

\section{Interplay between different levels of government in natural resource management}

In the case of the NYC Watershed, there were three levels of government present in the nutrient management regulatory process, the federal level (EPA), the State of New York, and the local governments (both NYC and the upstream watershed localities). The watershed nutrient loads for the reservoir were non-compliant to federal standards and the federal government imposed sanctions in the upstream watershed areas through restrictions and policies. These mandates created tension between the residents of NYC and the upstream communities, re-igniting historical tensions between the two regions within the watershed - with the town of Cannonsville being central to this conflict. Recognising the potential for negative outcomes associated with this process, the state government created a group of local, state, regional and federal stakeholders to engage with local residents. In this process, the state and federal officials respected and honoured local opinions, ideas, and knowledge consistently over time, developing a trusting relationship between these levels of governance. Local residents were provided 100 per cent cost sharing for implementing BMPs to ensure the nutrient TMDLs were compliant with federal levels. The state and federal agencies empowered local communities to create governance groups to manage issues, funding, and implementation of policies and BMPs. These local governance groups sought widespread representation, participation, and engagement with local citizens and landowners. At times there were bureaucratic federal fund use rules that created higher costs to implement changes in practice, but local communities were able to navigate these restrictions appropriately through engagement with local, state and federal governments. As we consider this case as a whole, state government served as a broker between federal and local governments in developing an effective engagement strategy to implement a system of local responses to regulations rather than relying on intrusive external, federal management.

In the case of the Chesapeake Bay Watershed, the governance system is much more complex due to the size of the watershed. In this case, the federal government is involved, along with six state governments and local community governments within these states. At issue are the TMDL loads in the watershed due to the local practices and non-compliance with local reduction practices. Natural resource management discourse in the Chesapeake Bay watershed reflects a historical context and narrative of federal regulation, creating conflict based on the issues of state versus federal government rights in creating and implementing policy. Additionally, in trying to meet the regulations, state governments disagree with one another as to how to approach issues, forcing the federal government to also act as a broker among state governments. In each state, there are coalitions of state-level interest groups that advocate competing uses for the watershed, pitting those with direct access to the Bay against those upstream in the larger watershed.

To capture the effects of efforts to reduce nutrient loads in the watershed, the federal government created the Chesapeake Bay Model. This simulation of the effects of local implementation of BMPs on nutrient and soil

\footnotetext{
42 A Armstrong and R Stedman, 'Landowner Willingness to Implement Riparian Buffers in a Transitioning Watershed’ (2012)
} 105 Landscape and Urban Planning 211, DOI: 10.1016/j.landurbplan.2011.12.011. 
loads in the Chesapeake Bay is maintained and modified by experts, with little input from local citizens. To address water quality issues, federal mandates, restrictions and regulations were implemented directly in local communities, forcing local citizens to change their practices with only partial cost sharing in the implementation process. Additionally, local citizens' voices are represented by a small number of local experts in the state and federal discussions. In local communities, interest groups are positioned oppositely, indicating that responsibility for the nutrient and soil loads were either municipal sewage or agricultural production based, often manifesting in a rural versus urban divide.

Overall, in this case, the federal government acts as both a regulator of local community practices and a broker between competing state-level governmental interests. Within states, there are both competing interests at the state level and local level, inhibiting collaboration among and within these levels of governance.

As we compare these two cases, there are stark differences in both the approach to governance and the interaction between the levels of government. The approach to developing and implementing policy in the NYC watershed emphasised broad, local government engagement, utilising both local citizen and expert knowledge to inform policy creation and implementation. In contrast, the Chesapeake Bay watershed method relied heavily on federal and state-level expert knowledge both in the creation and implementation of policy and practice, with little local governmental input into the process. The NYC watershed leveraged funding to provide full support for local implementation of BMPs, while the residents of the Chesapeake Bay receive a partial subsidy.

The interaction between the levels of government in the NYC watershed emphasised the state government as a broker between local and federal levels. However, in the case of the Chesapeake Bay, the federal government acts as a creator and implementer of regulations as well as a broker between multiple states, decreasing the ability for local governmental involvement in policy creation and implementation.

\section{Importance of engagement in policy creation and implementation}

The previous analysis alluded to engagement in policy creation and implementation, however this analysis specifically focuses on who was engaged in this process and how they were invited to participate. In the case of the NYC watershed, there was a historical resentment toward residents of NYC from those upstream in the watershed due to a previous experience that led to displacement of local upstream residents. This animosity was due to a lack of engagement of local residents by the state in the creation of the Cannonsville Reservoir, and those residents that were displaced viewed their hardship as a direct result of extra-local needs holding greater importance than their own. This resentment led to non-compliance of nutrient management practices, creating issues of water quality in the watershed. The state government learned from this experience and, in this newest conflict over issues of water access, engaged federal, state, regional and local individuals to create a plan, thus intentionally building a process that emphasised creation of trust and continued engagement amongst these groups. Leveraging funding from extra-local (NYC) sources was key to the process, as the residents of NYC were the ones receiving the largest benefit from local compliance and practices, indicating a partnership between these two localities rather than placing a preference on one region's needs over another.

The creation of local coalitions to voice ideas and concerns and uphold needs of upstream residents enhanced the ability of citizens to be part of the policy development and implementation process, ensuring local knowledge would be used to maximise the impact of the creation and use of BMPs. Local, intentional engagement of the farming community in these coalitions led to greater change of nutrient management practices. Additionally, experts utilised respectful engagement and educational practices to help local citizens understand and recognise the utility of scientific knowledge in the creation of BMPs. Overall, the use of local knowledge to develop solutions, while utilising respectful practices to help educate and engage local individuals with regards to expert and scientific knowledge and practices, increased positive water quality outcomes.

In the case of the Chesapeake Bay Watershed, there is a reliance on federal computer modelling (The Chesapeake Bay Model) for tracking trends in water quality. While there are certainly exceptions, local citizen knowledge is largely excluded from this modelling. The modelling identified the use of BMPs to be implemented at the local level to reduce water quality issues. These BMPs are developed by groups of experts, and local citizen feedback on the utility of these practices is largely ignored. Local citizens are forced to adopt 
these practices, with little regard for their local knowledge. Over time, the focus shifted to making the model more precise rather than exploring opportunities for local citizen feedback, leading to lack of implementation of new practices locally. In some instances, the prescribed BMPs (ie, minimising tillage) have the potential to increase runoff of soil nutrients, negatively affecting water quality. These complex issues on soil nutrient and water quality management are difficult for experts, let alone the general public to rationalise. There is a large focus on agricultural communities; the lack of engagement and financial incentivising of non-agricultural landowners decreases the likelihood of them changing practices on their land. The interests of local and state governments are not aligned and each publishes conflicting information about the sources of water pollution and efficacy of mitigation strategies. This confuses local landowners, leading to ineffective management of nutrients and soil runoff. However, there are pockets where local engagement is emphasised, and positive water quality outcomes are being realised. These successes often are due to a focus on water quality in the local streams, bringing relevance to the local communities, rather than focusing on the Chesapeake Bay as a whole. Overall, the reliance on expert knowledge and lack of engagement with local citizens created a focus on federal and state issues rather than local informed ideas for change in practices and outcomes.

Comparing these two cases, we can see very different approaches to engagement, both in regard to who was involved and how these individuals were involved. In the case of the NYC watershed, the state government learned from previous experiences, and relied on balancing the input of expert and local knowledge. They emphasised broad participation from multiple stakeholders to create and increase use of BMPs. In the Chesapeake Bay Watershed, the emphasis is heavily skewed to preference expert and scientific knowledge and modelling rather than local citizen knowledge.

In the NYC watershed, there was an appreciation for citizen needs and situations, both in terms of the needs of NYC residents for access to clean water as well as the livelihoods of upstream residents. By engaging local residents in respectful ways, greater participation has enhanced positive water quality outcomes. However, in the Chesapeake Bay watershed, often the lack of effective local citizen engagement and neglect of local knowledge has led to disenfranchisement of these citizens, reducing the likelihood of similar positive outcomes for the Chesapeake Bay.

\section{Discussion and concluding remarks}

Based on our analysis of the NYC and Chesapeake Bay watersheds across our two objectives, we offer several observations for discussion.

\section{Engagement with local citizens matters}

As we consider the two cases, one of the most important aspects associated with positive results in the two watersheds is engagement with local citizens. In each of these cases, when local residents were engaged in meaningful ways, nutrient loads in the watersheds were decreased. Engagement needs to be more than information sharing or surface-level involvement; it requires the intentional use of both local and expert knowledge to explore the best options for BMPs. By empowering local citizens to develop options for nutrient management and creating a trusting relationship between stakeholders, the NYC watershed process was much more successful in changing residents' practices than those in the Chesapeake Bay. However, in the Chesapeake Bay, the pockets of engagement with local citizens show the potential for improving water quality. We are seeing more and more examples in the Chesapeake Bay where government officials and experts are learning from previous experiences with local citizens. Working with local citizens can be a time- and labourintensive effort; yet, it is essential if we hope to increase the effectiveness of our nutrient management policy creation and implementation. Throughout this process, local and expert knowledge needs to work in tandem, rather than one being privileged relative to the other.

\section{The level of government acting as a broker affects mitigation processes}

Due to the complicated interaction between federal, state and local governments, especially in the US, each with their own constitutional and assumed roles in policy formation and implementation, the governmental level that acts as a broker between conflicting parties can affect the outcomes of environmental and natural resources mitigation processes. In the Chesapeake Bay watershed, the federal government's role was both as a regulator and enforcer of federal law, and a broker between competing state's interests. This causes the local 
level of governance to be largely left out of the nutrient management development process. It also creates a context that may be confounded by the role of federal and states' rights, adding a level of conflicting interest between state and federal governments due to jurisdictional issues. This may interfere with the ability of the federal government to effectively broker between states and also implement regulations. While the NYC watershed was smaller in scope with regards to its complexity of governmental interactions, the state acted as a broker between federal and local governments, removing a potential complication; that is, the issue of local use of BMPs to meet federal TMDL guidelines. The governmental level serving as a broker affects the political, administrative and scientific interactions in the nutrient management policy formation and implementation process, and care should be taken in these processes to ensure that brokering does not impede on the progress of these efforts.

\section{Cost sharing is a key component}

Changing local nutrient management practices is a costly endeavour, not only in terms of policy and regulation formation and implementation, but also in real terms with the citizens that must implement the new practices. The issue of who pays for these costs is a key element in the process. In the NYC watershed, the residents of NYC, through fee collection, supplied funding for upstream BMP implementation, with a full subsidy to citizens. In the Chesapeake Bay watershed, only partial subsidisation for citizens exists. Additionally, the funding for this subsidy is a cause of conflict between the states as to who should bear the greatest burden due to the sources for pollution among the states in the watershed. When developing nutrient management policy, funding strategies for implementation of the BMPs is a key consideration, which may affect the policy outcomes.

\section{Dignity is an important consideration in engagement}

Respect for citizens and the situations in which they exist, recognising their inherent dignity, is a key component to the engagement process. During the nutrient management policy and implementation process, an understanding of local contexts for the use of existing practices is important before they can effectively be changed. When the residents of the NYC watershed were engaged in ways that recognised and respected the historical context of their non-compliance, the upstream citizens began to develop the trust once lost for the NYC, state and federal governments, building the groundwork for future collaborations. Additionally, the lack of engagement in the Chesapeake Bay watershed with local, everyday citizens is likely decreasing the effectiveness of management policy in this watershed. Emphasising expert knowledge and being dismissive of local knowledge creates an adversarial relationship between local citizens and extra-local governments; wellintended regulation can drive negative consequences.

\section{Concluding remarks}

We have sought to explore how the interplay between different levels of government and citizen engagement affects natural resource management policy creation and implementation through the exploration of two case studies that examine nutrient management policy in the US. While these may be regarded as two special cases, the NYC and Chesapeake Bay watersheds are two of the largest in the nation and exemplify these two important components of policy formation and implementation. Through these cases and our analysis, we have demonstrated that engagement with local citizens matters, and it is an essential component to increasing the effectiveness of policy outcomes. The interplay between government levels with regards to the brokering of competing interests can have a significant effect on the policy implementation process, and must be a key factor in the policy development and implementation process. The issue of cost for implementation of BMPs for local citizens must be considered to increase the compliance with these practices. Finally, how citizens are engaged and respected in the process is vital, and must be reflected in both the creation and implementation of policy to develop a culture of trust and collaboration for future endeavours.

The issue of natural resource management policy creation and implementation is a complicated, wicked problem. When we focus solely on one aspect of the issues associated with protecting our environment and natural resources, we neglect important aspects that can affect outcomes of our efforts, both positively and negatively. It is essential that, as we seek to create policy and regulatory approaches, we also consider the human and institutional dimension of environmental and natural resource management issues, as well as the broader socio-political context in which NRM policies and programs operate. In practice, this may lengthen our 
time for policy creation and implementation, but this time may be well spent, as it may increase the potential for positive outcomes in alleviating natural resource issues.

We recognise the limitations presented by this research. First, these two specific cases highlight contrasting local engagement strategies; additional research could include cases that fall between these extremes, exploring the issues and successes of implementation of a broader representation of multiple types of NRM policy creation and implementation strategies. Second, as in any case study research, this research has limitations to inference. ${ }^{43}$ We cannot say that what we see in these two cases is definitive, but it is suggestive. The strength of utilising case study methodology in this research is that it grounds theory and concept in real world situations and helps us sharpen our understandings and, furthermore, it helps us identify key questions and issues for examination and study going forward. Third, the relative institutional complexity of the Chesapeake Bay watershed case as compared to the NYC watershed case, given all of the states involved in the Chesapeake Bay case, may make the two cases not exactly comparable. Fourth, community engagement and natural resource management policy and governance research is necessarily complex. Understanding perceptions of the regulated and non-regulated community members regarding the history and culture of a particular area as they pertain to a question of NRM implementation is vital to crafting successful policies. Therefore, research efforts to guide implementation will need to consider those perceptions when attempting to understand linkages between governance decisions and the likely success of implementation efforts. Those research efforts must necessarily involve 'local experts' to assist in the development of appropriate research approaches and inquiries so that important nuanced understandings needed to guide the work are not neglected. Finally, for this study, we have used a notion of engagement that requires citizens to be robustly involved in the policy development and implementation process, with the idea that such involvement will bring local knowledge, experience, and insight into the discussions and decisions for the better. There are other views of what constitutes legitimate engagement, providing information but no reciprocity is at the other end of the continuum to what we are arguing for. The notion of and approach to engagement are themselves contested, as is their implications for policy outcomes. Continued research to elucidate the effectiveness of outcomes from these types of engagement strategies will help us to refine our efforts to mitigate natural resource management issues.

\footnotetext{
${ }^{43}$ R K Yin, Case Study Research: Design and Methods (SAGE Publications, $4^{\text {th }}$ ed, 2006).
} 